\title{
Over-expression of miR-124 impairs proliferation, invasion and epithelial-mesenchymal transition in pituitary prolactinoma by targeting PHD finger protein 19
}

\author{
Zongxi Li ${ }^{1}$, Lingxuan Ren ${ }^{2}$, Shoujie Wang ${ }^{3 *}$ \\ ${ }^{1}$ Department of Neurosurgery, Clinical Medical College and The First Affiliated Hospital of Chengdu Medical College, Chengdu \\ City, Sichuan Province 610500, ${ }^{2}$ Department of Child Healthcare, Cheng Du Xin Du Maternal \& Child Health Care Hospital, \\ Chengdu City, Sichuan Province 610500, ${ }^{3}$ Department of Neurosurgery, The Second Affiliated Hospital of Air Force Military \\ Medical University, Xi'an City, Shaanxi Province 710038, China
}

*For correspondence: Email: sjwang2366@163.com; Tel: +86-029-84717846

Sent for review: 8 February 2021

Revised accepted: 8 April 2021

\begin{abstract}
Purpose: To determine the effect of miR-124 in pituitary prolactinoma.

Methods: The viability and proliferation of prolactinoma cells were investigated using Cell Counting Kit8 and 5-ethynyl-2'-deoxyuridine staining assays. Cell migration and invasion were investigated using the transwell assay. The epithelial-mesenchymal transition was investigated using western blotting. The target gene of miR-124 was verified by the luciferase activity assay.

Results: The viability and proliferation of prolactinoma cells were repressed by miR-124 overexpression $(p<0.01)$. Forced miR-124 expression suppressed prolactinoma cell migration and invasion $(p<0.01)$. E-cadherin expression was enhanced, while $N$-cadherin and vimentin were reduced, by miR124 over-expression $(p<0.01)$. PHF19 (plant homeodomain-like finger protein 19) contains an miR-124 binding site, and PHF19 over-expression enhanced cell proliferation, promoted cell migration and invasion, reduced E-cadherin expression and enhanced $\mathrm{N}$-cadherin and vimentin expression in prolactinoma cells. Additionally, miR-124 mimic-induced suppression of prolactinoma cell growth and metastasis was attenuated by forced PHF19 expression.

Conclusion: MiR-124 retards prolactinoma cell growth and metastasis by reducing PHF19, providing a promising therapeutic target for prolactinoma.
\end{abstract}

Keywords: miR-124, PHF19, Pituitary prolactinoma, Cell proliferation, Cell invasion, Cell migration

\begin{abstract}
This is an Open Access article that uses a fund-ing model which does not charge readers or their institutions for access and distributed under the terms of the Creative Commons Attribution License (http://creativecommons.org/licenses/by/4.0) and the Budapest Open Access Initiative (http://www.budapestopenaccessinitiative.org/read), which permit unrestricted use, distribution, and reproduction in any medium, provided the original work is properly credited.
\end{abstract}

Tropical Journal of Pharmaceutical Research is indexed by Science Citation Index (SciSearch), Scopus, International Pharmaceutical Abstract, Chemical Abstracts, Embase, Index Copernicus, EBSCO, African Index Medicus, JournalSeek, Journal Citation Reports/Science Edition, Directory of Open Access Journals (DOAJ), African Journal Online, Bioline International, Open-J-Gate and Pharmacy Abstracts

\section{INTRODUCTION}

Pituitary adenomas are common intracranial neoplasms, accounting for $15 \%$ of all intracranial tumors in China [1]. Prolactinoma is the most common type of pituitary adenoma and contributes to approximately $50 \%$ of all pituitary adenomas [2]. Tumor cells often surround the internal carotid artery or invade into the cavernous sinus, resulting in higher recurrence and aggressiveness of prolactinoma [3]. Therefore, inhibition of the invasive behavior of prolactinoma cells is a challenge to clinicians for preventing prolactinomas. 
MicroRNAs (miRNAs) are potential biomarkers for pituitary tumors [4]. The regulatory role of miRNAs in prolactinoma progression has been widely investigated. A previous study showed that miR-124 is a tumor suppressor in bladder cancer [5], and miR-124 suppressed glioblastoma multiforme cell proliferation [6]. However, the effect of miR-124 on prolactinoma has not yet been reported. Plant homeodomainlike finger protein 19 (PHF19, also called PCL3) is a homolog of polycomb-like proteins that participates in the cell cycle and development through epigenetic regulation of homeotic genes [7]. Additionally, PHF19 has been implicated in miR-124a-mediated glioma cell proliferation [8]. Therefore, we hypothesized that miR-124 might suppress prolactinoma cell growth and metastasis by down-regulating PHF19.

\section{EXPERIMENTAL}

\section{Cell culture and transfection}

Rat $M M Q$ and $\mathrm{GH} 3$ cells were cultured in $\mathrm{F}-12 \mathrm{~K}$ culture medium (Beyotime Institute of Biotechnology, Haimen, China) containing $10 \%$ horse serum and $5 \%$ fetal bovine serum (Beyotime Institute of Biotechnology) in a $37^{\circ} \mathrm{C}$ incubator. MiR-124 mimic and inhibitor were synthesized by Invitrogen (Carlsbad, CA, USA). Cells $\left(3 \times 10^{5}\right.$ cells/well) were transfected with 20 $\mathrm{nM}$ of miR-124 mimic or inhibitor or $300 \mathrm{nM}$ pcDNA-PHF19 (Invitrogen) using Lipofectamine 2000 (Invitrogen).

\section{Cell viability and proliferation}

Cells with the indicated transfection were seeded in 96-well plates for 24, 48, or $72 \mathrm{~h}$. Cell Counting Kit-8 solution (Sigma Aldrich, St. Louis, MO, USA) was added and incubated for another $2 \mathrm{~h}$. Next, the optical density at $490 \mathrm{~nm}$ was measured. To evaluate cell proliferation, cells were seeded in 96-well plates for $24 \mathrm{~h}$ and then incubated with medium containing $100 \mu \mathrm{L}$ of 5 ethynyl-2'-deoxyuridine EdU (50 $\mu \mathrm{M}$; Invitrogen) for $12 \mathrm{~h}$. Following fixation in $4 \%$ paraformaldehyde, the cells were permeabilized and then incubated with Apollo $® 488$ fluorescent staining solution (Beyotime Institute of Biotechnology). The nuclei were stained with 4',6-diamidino-2-phenylindole, and the cells were then observed under a fluorescence microscope (Nikon, Tokyo, Japan).

\section{Cell migration and invasion}

Cells with the indicated transfection were seeded in Matrigel-precoated (BD Biosciences, Bedford,
MA, USA) chambers (Corning, Tewksbury, MA, USA) for $48 \mathrm{~h}$. The paraformaldehyde-fixed and crystal violet-stained invasive cells were imaged under a microscope (Olympus). For cell migration, the cells were seeded in the chamber without Matrigel precoating.

\section{Luciferase reporter assay}

Wild-type or mutant sequences of the $3^{\prime}$ untranslated region (3' UTR) of PHF19 were subcloned into pmiR-RB-REPORT (Riobio, Guangzhou, China) and were called PHF19 3'UTR WT or PHF19 3'UTR MUT, respectively. The vectors were cotransfected with miR-124 mimic or inhibitor into HEK-293T cells, and the Dual-Luciferase Reporter Assay System (Promega, Madison, Wisconsin, USA) was used to determine the luciferase activity.

\section{Quantitative reverse transcription- polymerase chain reaction (qRT-PCR)}

MiRNAs were extracted from cells, and the mRNAs were then reverse transcribed into cDNAs. Analysis of miR-124 expression was performed using SYBR Green Master Mix (Roche, Mannheim, Germany) relative to U6. The primer sequences are shown in Table 1.

Table 1: Primer sequences for PCR

\begin{tabular}{ll}
\hline ID & Sequence $\left(5^{\prime}-\mathbf{3}^{\prime}\right)$ \\
\hline miR-124 Forward & TGACTTCAACAGCGCA \\
miR-124 Reverse & CCCA \\
CACCCTGTTGCTGTAGC \\
U6 Forward & CAAA \\
U6 Reverse & AACGCTTCGGCAGCACA \\
& CGT \\
\hline
\end{tabular}

\section{Western blotting}

MMQ and GH3 cell lysates were separated using electrophoresis, followed by transfer to polyvinylidene difluoride membranes. The membranes were incubated with primary antibodies against PHF19, E-cadherin, Ncadherin, vimentin, and $\beta$-actin (Cell Signaling Technology, Danvers, MA, USA). Horseradish peroxidase-linked secondary antibody (Cell Signaling Technology) was used to incubate the membranes, and an enhanced chemiluminescence detection kit (Pierce; Thermo Fisher Scientific) was used to analyze the immunoreactivities of bands in the membranes.

\section{Statistical analysis}

The data are presented as means \pm standard error of the mean. Student's t-test or one-way 
analysis of variance was used to analyze the difference between groups. $P<0.05$ was considered significant.

\section{RESULTS}

Forced miR-124 represses the cell proliferation of pituitary prolactinoma

qRT-PCR analysis showed higher expression of miR-124 by miR-124 mimic than NC mimic and mock (Figure $1 \mathrm{~A}$ ). Functional assays indicated that ectopic expression of miR-124 reduced the viability of $\mathrm{MMQ}$ and $\mathrm{GH} 3$ cells (Figure $1 \mathrm{~B}$ ). Additionally, EdU-positive MMQ and $\mathrm{GH} 3$ cells transfected with miR-124 mimic were lower than those transfected with NC mimic (Figure $1 \mathrm{C}$ ), suggesting that forced miR-124 repressed pituitary prolactinoma cell proliferation.
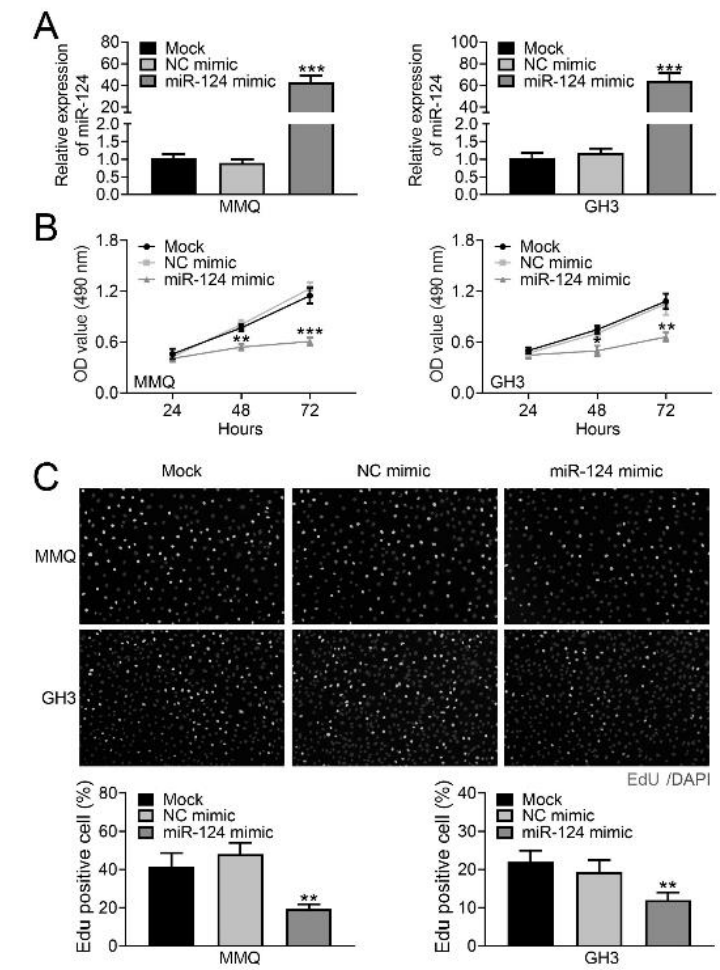

miR-124 mimic

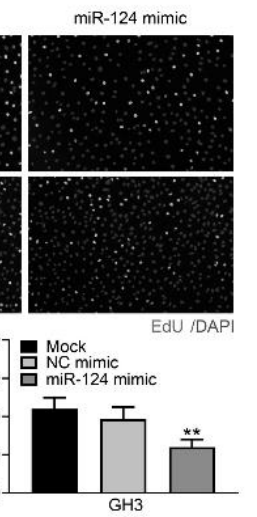

Figure 1: Forced miR-124 expression represses the cell proliferation of pituitary prolactinoma. (A) Higher miR-124 expression in cells transfected with miR-124 mimic than with NC mimic and mock. (B) miR-124 over-expression decreased the $\mathrm{MMQ}$ and $\mathrm{GH} 3$ cell viability. (C) miR-124 over-expression decreased the number of EdU-positive MMQ and GH3 cells; * $p$ < $0.05,{ }^{* *} p<0.01,{ }^{* * *} p<0.001$

\section{Forced miR-124 represses the cell migration} and invasion of pituitary prolactinoma

The transwell assay showed the suppressive effect of miR-124 on prolactinoma cell migration
(Figure 2A) and invasion (Figure 2B). Additionally, miR-124 over-expression increased the E-cadherin protein expression and reduced $\mathrm{N}$-cadherin and vimentin protein expression (Figure $2 \mathrm{C}$ ), indicating the anti-invasive role of miR-124 in pituitary prolactinoma.

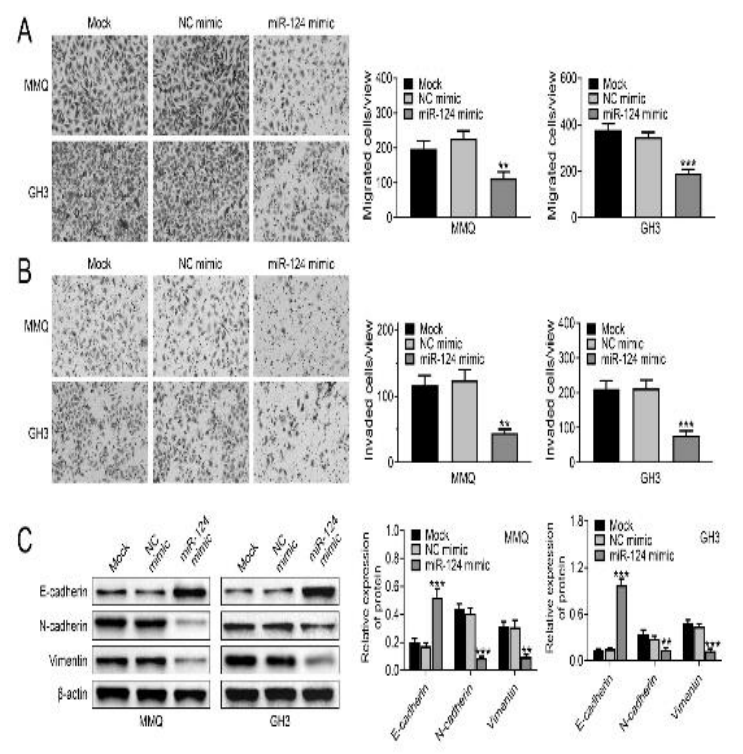

Figure 2: Forced miR-124 represses the cell migration and invasion of pituitary prolactinoma. (A) miR-124 over-expression decreased $\mathrm{MMQ}$ and $\mathrm{GH} 3$ cell migration. (B) miR-124 over-expression decreased MMQ and GH3 cell invasion. (C) miR-124 overexpression increased $\mathrm{E}$-cadherin and decreased $\mathrm{N}$ cadherin and vimentin expression in $\mathrm{MMQ}$ and $\mathrm{GH} 3$ cells; ${ }^{* *} p<0.01,{ }^{* * *} p<0.001$

\section{MiR-124 binds to PHF19}

Bioinformatics analysis (TargetScan: http://www.targetscan.org/vert_72/) demonstrated that miR-124 binds to the 3'UTR of PHF19 (Figure 3A). miR-124 over-expression reduced the luciferase activity of PHF19 3'UTR WT (Figure 3B), while miR-124 inhibition enhanced its luciferase activity (Figure 3B). However, the activity of PHF19 3'UTR MUT was not affected by either miR-124 mimic or inhibitor (Figure 3B). Additionally, the suppressive effect of miR-124 on PHF19 expression and promotive effect of miR-124 silencing on PHF19 expression in $M M Q$ and $\mathrm{GH} 3$ cells (Figure $3 \mathrm{C}$ ) suggest that miR-124 directly binds to PHF19 in pituitary prolactinoma.

\section{Forced PHF19 attenuates the suppressive effect of miR-124 on pituitary prolactinoma progression}

Western blot analysis showed higher protein expression of PHF19 by transfection with 
pcDNA-PHF19 than with the empty vector (Figure 4 A). PHF19 over-expression increased MMQ cell viability (Figure $4 \mathrm{~B}$ ), enhanced the number of EdU-positive cells (Figure $4 \mathrm{C}$ ), and promoted cell migration (Figure $4 \quad \mathrm{D})$ and invasion (Figure $4 \mathrm{E}$ ). Additionally, E-cadherin protein expression was reduced in $\mathrm{MMQ}$ transfected with pcDNA-PHF19, while $\mathrm{N}$ cadherin and vimentin protein expression was enhanced (Figure $4 \mathrm{~F}$ ). Cotransfection with miR124 mimic and pcDNA-PHF19 attenuated the suppressive effects of miR-124 on pituitary prolactinoma cell viability (Figure $4 \quad$ B), proliferation (Figure $4 \mathrm{C}$ ), migration (Figure $4 \mathrm{D}$ ), and invasion (Figure $4 \mathrm{E}$ ). Additionally, enhanced $\mathrm{E}$-cadherin and reduced $\mathrm{N}$-cadherin and vimentin expression in MMQ transfected with miR-124 was also reversed by cotransfection with miR124 mimic and pcDNA-PHF19 (Figure 4 F). These results suggest that miR-124 retarded pituitary prolactinoma progression by negative regulating PHF19.

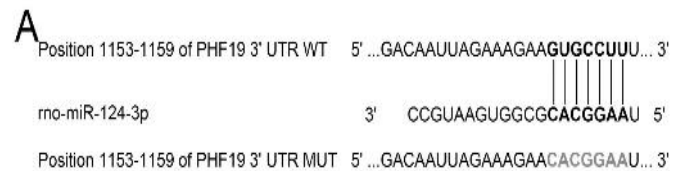

$\mathrm{B}_{2}$
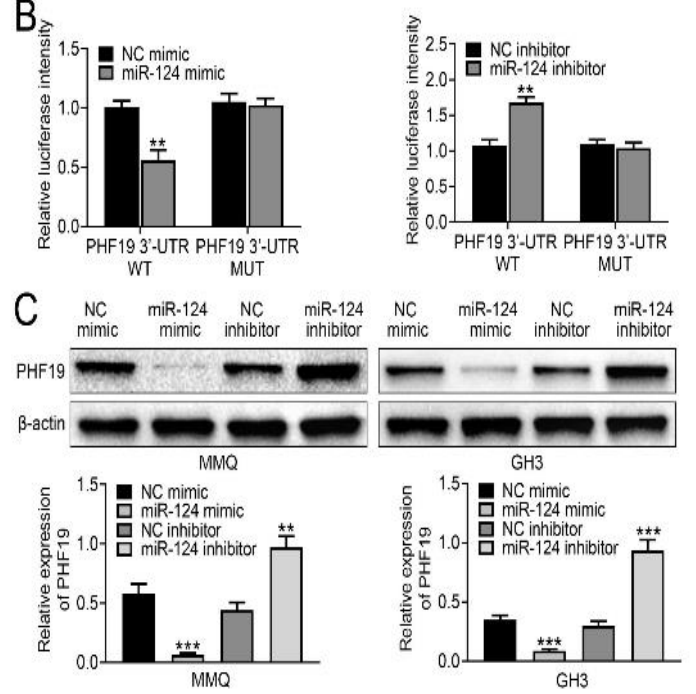

Figure 3: MiR-124 binds to PHF19. (A) Potential binding site of miR-124 on PHF19 from bioinformatics analysis using TargetScan (http://www.targetscan.org/vert_72/). (B) Transfection with miR-124 mimic decreased the luciferase activity of PHF19 3'UTR WT, while transfection with miR-124 inhibitor increased the luciferase activity of PHF19 3'UTR WT. The activity of PHF19 3'UTR MUT was not affected by either miR-124 mimic or inhibitor. (C) miR124 over-expression decreased PHF19, while miR124 inhibition increased PHF19 in MMQ and $\mathrm{GH} 3$ cells; ${ }^{* *} p<0.01,{ }^{* * *} p<0.001$
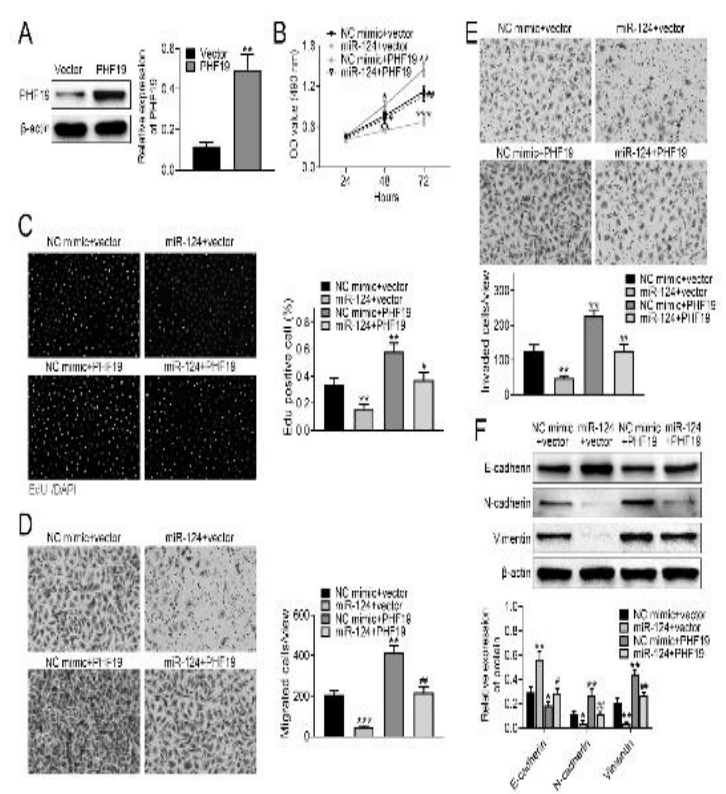

Figure 4: Forced PHF19 expression attenuates the suppressive effect of miR-124 on pituitary prolactinoma progression. (A) Higher PHF19 protein expression following transfection with pcDNA-PHF19 than with empty vector over-expression. (B) PHF19 increased $M M Q$ cell viability and attenuated miR-124induced decrease in MMQ cell viability. (C) PHF19 over-expression increased MMQ cell proliferation and attenuated the miR-124-induced decrease in MMQ cell proliferation. (D) PHF19 over-expression increased $M M Q$ cell migration and attenuated the miR-124induced decrease in MMQ cell migration. (E) PHF19 over-expression increased $\mathrm{MMQ}$ cell invasion and attenuated the miR-124-induced decrease in MMQ cell invasion. (F) PHF19 over-expression reduced Ecadherin and enhanced $\mathrm{N}$-cadherin and vimentin expression in MMQ cells and attenuated miR-124induced enhancement of E-cadherin and reduction of $\mathrm{N}$-cadherin and vimentin expression in MMQ cells; ${ }^{*} \# p$ $<0.05,{ }^{* *}, \# \#<0.01,{ }^{* * *} p<0.001$

\section{DISCUSSION}

Dysregulated miRNA expression is a hallmark of pituitary prolactinoma, and miRNAs function as either oncogenes or tumor suppressors in pituitary prolactinoma [4]. Considering the tumorrepressive effect of miR-124 on various tumors, the detailed mechanism of miR-124 on pituitary prolactinoma progression was evaluated in this study.

Circulating miRNAs are considered diagnostic or prognostic biomarkers in pituitary tumors [9]. Because miR-124 is a potential diagnostic biomarker in colorectal cancer [10], the clinical relationship between miR-124 and prolactinoma patients should be investigated to validate the diagnostic or prognostic role of miR-124 in prolactinoma. Functional assays have indicated 
the tumor-suppressive role of miR-124 on prolactinoma. The epithelial-mesenchymal transition confers metastatic properties on tumor cells and is implicated in carcinogenesis through resistance to apoptotic stimuli and enhanced mobility and invasion [11]. MicroRNA-124 suppresses the metastatic properties of prolactinoma with enhanced E-cadherin and reduced $\mathrm{N}$-cadherin and vimentin expression. Therefore, miR-124 may be a therapeutic target of prolactinoma.

Multiple PHFs promote tumorigenesis through epigenetic regulation of target genes [12-14]. The Tudor domain of PHF19 binds to histone H3K36me3 [15], enhancing H3K27me3 deposition to promote the tumorigenicity of multiple myeloma [16]. PHF19 inhibition is involved in the anti-oncogenic role of miR-195-5p in hepatocellular carcinoma progression [17]. We showed that miR-124 binds to the 3'UTR of PHF19, and the silencing of miR-124 promotes PHF19 expression in prolactinoma cells. Further functional assays demonstrated that PHF19 promotes the tumorigenesis of prolactinoma through enhanced cell viability, proliferation, migration, invasion and EMT. PHF19 suppression by $\mathrm{miR}-124 \mathrm{a}$ retards glioma cell proliferation [8]. This study showed that forced PHF19 attenuates the suppressive effect of miR124 on pituitary prolactinoma progression. Therefore, miR-124 retards pituitary prolactinoma progression by negatively regulating PHF19.

miR-124 methylation is a biomarker of cervical cancer [18], and methylation-modulated silencing of miR-124 facilitates pancreatic cancer metastasis and progression [19]. Deoxyribonucleic acid methylation in the promoter of miR-124 promotes Tat-mediated activation of microglia [20]. Therefore, whether PHF19 epigenetically regulates miR-124 methylation to promote prolactinoma progression requires further investigation. JAK-STAT signaling is implicated in PHF19-mediated multiple myeloma tumorigenicity [16]. The downstream target pathway involved in miR124/PHF19 axis-modulated prolactinoma progression should also be validated in further studies.

\section{CONCLUSION}

The current work characterized the tumorsuppressive role of $\mathrm{miR}-124$ as well as the oncogenic role of PHF19 in prolactinoma progression. MicroRNA-124/PHF19 axis may yield a promising approach to suppress prolactinoma progression.

\section{DECLARATIONS}

\section{Acknowledgement}

Thanks are due to Mr. Amjad Farooq for his technical assistance, and BioMES, Alpha Genomics Private Limited, Islamabad - Pakistan for editing and reviewing the manuscript. Thanks are also due to the patients who participated in the study.

\section{Conflict of interest}

No conflict of interest is associated with this work.

\section{Availability of data and materials}

All the data generated or analyzed during this study are included in this published article.

\section{Contribution of authors}

We declare that this work was performed by the authors named in this article and that all liabilities pertaining to claims relating to the content of this article will be borne by the authors. Zongxi Li and Shoujie Wang designed the study and supervised the data collection. Lingxuan Ren analyzed and interpreted the data. Zongxi Li, Lingxuan Ren, and Shoujie Wang prepared the manuscript for publication and reviewed the draft of the manuscript. All the authors have read and approved the manuscript.

\section{Open Access}

This is an Open Access article that uses a funding model which does not charge readers or their institutions for access and distributed under the terms of the Creative Commons Attribution License (http://creativecommons.org/licenses/by/ 4.0) and the Budapest Open Access Initiative (http://www.budapestopenaccessinitiative.org/rea d), which permit unrestricted use, distribution, and reproduction in any medium, provided the original work is properly credited.

\section{REFERENCES}

1. Jin Z, Wu X, Wang Y. Clinical study of endoscopic treatment of a sellar pituitary adenomas with sellar diaphragm defect. BMC Neurol 2020; 20(1): 129.

2. Chatzellis E, Alexandraki KI, Androulakis II, Kaltsas G. Aggressive Pituitary Tumors. Neuroendocrinology 2015; 101(2): 87-104.

3. Kreutzer J, Fahlbusch R. Diagnosis and treatment of pituitary tumors. Curr Opin Neurol 2004; 17(6).

Trop J Pharm Res, April 2021; 20(4): 725 
4. Beylerli O, Beeraka NM, Gareev I, Pavlov V, Yang G, Liang Y, Aliev G. MiRNAs as Noninvasive Biomarkers and Therapeutic Agents of Pituitary Adenomas. Int $\mathrm{J} \mathrm{Mol}$ Sci 2020; 21(19): 7287.

5. Zhang T, Wang J, Zhai X, Li H, Li C, Chang J. MiR-124 retards bladder cancer growth by directly targeting CDK4. Acta Bioch Bioph Sin 2014; 46(12): 1072-1079.

6. Silber J, Lim DA, Petritsch C, Persson Al, Maunakea AK, Yu $M$, Vandenberg $S R$, Ginzinger $D G$, James $C D$, Costello JF et al. miR-124 and miR-137 inhibit proliferation of glioblastoma multiforme cells and induce differentiation of brain tumor stem cells. BMC Mede 2008; 6: 14-14.

7. Wang $S$, Robertson GP, Zhu J. A novel human homologue of Drosophila polycomblike gene is upregulated in multiple cancers. Gene 2004; 343(1): 6978.

8. Lu J, Ji H, Tang H, Xu Z. microRNA-124a suppresses PHF19 over-expression, EZH2 hyper-activation, and aberrant cell proliferation in human glioma. Biochem Bioph Res Co 2018; 503(3): 1610-1617.

9. Di leva A, Butz $H$, Niamah $M$, Rotondo $F$, De Rosa S, Sav A, Yousef GM, Kovacs K, Cusimano MD. MicroRNAs as Biomarkers in Pituitary Tumors. Neurosurgery 2014; 75(2): 181-189.

10. Qin Z, Liu X. miR-124, a potential therapeutic target in colorectal cancer. Oncotargets Ther 2019; 12: 749-751.

11. Mittal V. Epithelial Mesenchymal Transition in Tumor Metastasis. Annu Rev Pathol-Mech 2018; 13(1): 395412.

12. Liu R, Gao J, Yang Y, Qiu R, Zheng $Y$, Huang $W$, Zeng $Y$, Hou $Y$, Wang $S$, Leng $S$ et al. PHD finger protein 1 (PHF1) is a novel reader for histone H4R3 symmetric dimethylation and coordinates with PRMT5WDR77/CRL4B complex to promote tumorigenesis. Nucleic Acids Res 2018; 46(13): 6608-6626.

13. Nagashima $M$, Shiseki $M$, Pedeux RM, Okamura $S$, Kitahama-Shiseki M, Miura K, Yokota J, Harris CC. A novel PHD-finger motif protein, p47ING3, modulates p53-mediated transcription, cell cycle control, and apoptosis. Oncogene 2003; 22(3): 343-350.

14. Zhang L, Huang $Q$, Lou J, Zou L, Wang $Y$, Zhang $P$, Yang G, Zhang J, Yu L, Yan D et al. A novel PHD-finger protein 14/KIF4A complex overexpressed in lung cancer is involved in cell mitosis regulation and tumorigenesis. Oncotarget 2017; 8(12): 19684-19698.

15. Qin S, Guo Y, Xu C, Bian C, Fu M, Gong S, Min J. Tudor domains of the PRC2 components PHF1 and PHF19 selectively bind to histone H3K36me3. Biochem Bioph Res Co 2013; 430(2): 547-553.

16. Ren Z, Ahn JH, Liu H, Tsai Y-H, Bhanu NV, Koss B, Allison DF, Ma A, Storey AJ, Wang $P$ et al. PHF19 promotes multiple myeloma tumorigenicity through PRC2 activation and broad H3K27me3 domain formation. Blood 2019; 134(14): 1176-1189.

17. Xu H, Hu Y-W, Zhao J-Y, Hu X-M, Li S-F, Wang Y-C, Gao J-J, Sha Y-H, Kang CM, Lin L et al. MicroRNA-195$5 p$ acts as an anti-oncogene by targeting PHF19 in hepatocellular carcinoma. Oncol Rep 2015; 34.

18. Rogeri $C D$, Silveira HCS, Causin RL, Villa LL, Stein MD, de Carvalho AC, Arantes LMRB, Scapulatempo-Neto C, Possati-Resende JC, Antoniazzi $M$ et al. Methylation of the hsa-miR-124, SOX1, TERT, and LMX1A genes as biomarkers for precursor lesions in cervical cancer. J Gynecol Oncol 2018; 150(3): 545-551.

19. Wang P, Chen L, Zhang J, Chen H, Fan J, Wang K, Luo J, Chen Z, Meng Z, Liu L. Methylation-mediated silencing of the miR-124 genes facilitates pancreatic cancer progression and metastasis by targeting Rac1. Oncogene 2014; 33(4): 514-524.

20. Periyasamy $P$, Thangaraj A, Guo M-L, Hu G, Callen S, Buch S. Epigenetic Promoter DNA Methylation of miR124 Promotes HIV-1 Tat-Mediated Microglial Activation via MECP2-STAT3 Axis. J Neurosci 2018; 38(23): 53675383. 